lesão esplênica em 446 (31,1\%) e lesão de vias urinárias em 122 (8,5\%). Em 207 casos (14,4\%) houve lesão combinada de fígado e baço. A lesão diafragmática esteve presente em 108 casos (7,5\%) e a lesão intestinal e/ou de mesentério em 154 casos (10,7\%). Foi realizado procedimento cirúrgico abdominal em 207 casos $(14,4 \%)$. 0 choque hipovolêmico representou o maior grupo de causa mortis, com 465 casos $(31,4 \%)$, seguido por politraumatismo, com 385 (26,9\%). Nos casos em que a causa jurídica do óbito foi recuperada $(31,1 \%)$, o atropelamento foi responsável por 70,6\% dos mesmos e colisões por 17,5\%. Este estudo ressalta o acometimento de múltiplas vísceras; abdominais em vítimas de acidentes de trânsito e a significância da perda volêmica como causa de óbito neste grupo de pacientes.

\title{
TEMA LIVRE POSTER
}

\section{HERNIORRAFIA INCISIONAL: TÉCNICA DE TRANSPOSIÇÃO PERITÔNIO- APONEURÓTICA LONGITUDINAL BILATERAL EM TRÊS PLANOS.}

Reis, NN.; Rodrigues, HLR.; Costa Júnior, JM.; Lázaro da Silva, A.

HMC-FUPEC-MG.

Hérnia incisional é uma importante complicação da laparotomia. Hérnias pequenas podem ser tratadas com aproximação das bordas musculofasciais. Hérnias maiores exigem técnicas sofisticadas.Objetivo: apresentar descrição da técnica.

Métodos: incisão longitudinal retirando-se a cicatriz; exposição do saco herniário e aponeuroses dos músculos retos do abdome e oblíquos externos; abertura longitudinal do saco e anel herniários; secção das aderências expondo as faces peritoneais dos músculos retos do abdome; revisão da cavidade; tração da borda mais livre do saco herniário; fazer incisão longitudinal na aponeurose posterior do $\mathrm{m}$. reto do abdome 1 a $2 \mathrm{~cm}$ de sua borda medial; no lado oposto incisar igualmente a aponeurose anterior do $\mathrm{m}$. reto do abdome; suturar no plano profundo o retalho peritonio fibroso ao retalho lateral posterior contralateral; suturar nos planos intermediários os retalhos mediais, anterior de um lado com o posterior contralateral; suturar no plano superficial o outro retalho peritoniofibroso com o anterior e lateral contralateral. Conclusão: esta técnica é reservada às hérnias gigantes. Suas vantagens incluem o uso de material autógeno; facilidade técnica; é a mais anatômica; baixo custo operacional e baixo índice de recidiva - 3,6\%, segundo a literatura.

\section{OBITOS POR HEMORRAGIA ABDOMINAL EM VITIMAS DE TRANSITO ATENDIDAS EM SERVIÇOS MÉDICOS DE URGÊNCIA.}

Rodrigues Júnior, JB.; Roque, FS.; Drumond, DAF.; Bordoni, LS.; Oliveira, ACMB.

\section{Hospital João XXIII / Instituto Médico Legal, Belo Horizonte, Minas Gerais, Brasil.}

A lesão intra-abdorninal representa importante foco de sangrarnento, onde a pronta atuação médica a fim de controlar a hemorragia pode ser decisiva. No entanto, apesar do atendimento correto, muitos pacientes acabam evoluindo para o óbito. A fim de estudar estes casos, foram analisadas 274 laudos de necropsias realizadas no período de janeiro de 1997 a dezembro de 1998 no WL-BH, onde a causa da morte foi choque hipovolêmico e o paciente foi atendido em algum serviço médico de urgência. 0 sangramento abdominal foi considerado responsável pelo óbito em 40 pacientes. Houve lesão esplênica em 23 casos (57,5\%), lesão hepática em 24 casos $(60 \%)$ e lesão de vias urinárias em 10 casos $(25 \%)$. A lesão diafragmática esteve presente em 2 casos (5\%) e a lesão intestinal e/ou de mesentério em 10 casos. Foi realizado procedimento cirúrgico em 13 casos (32,5\%). A fratura pélvica esteve presente em 13 casos (32,5\%). Apenas 3 casos apresentaram lesões de vísceras sólidas isoladas, sendo 1 caso de lesão esplênica e 2 de lesão hepática. $\mathrm{Na}$ amostra estudada o óbito por hemorragia intra-abdorninal ocorreu preferencialmente por mais de uma fonte de sangramento. 


\title{
PERDA DE PESO APÓS CIRURGIA PARA OBESIDADE MÓRBIDA: TÉCNICA DE CAPELLA.
}

\author{
Borges,VF.; Campos, APC.; Oliveira Filho, JBG.; Silva, EN.; Câmara, HEB.
}

INTRODUÇÃO: A obesidade mórbida, epidemia dos tempos modernos, requer tratamento cirúrgico em $90 \%$ dos casos, encontrando resultados mais duradouros que o tratamento clínico. OBJETIVO: Demonstrar a eficácia da cirurgia na obesidade mórbida em grupo de 149 pacientes tratados no Serviço da Santa Casa de Belo Horizonte. MÉTODOS: O estudo foi realizado em 149 pacientes operados no período de agosto de 99 a fevereiro de 2002, sendo 101 mulheres, entre 16-68 anos (média-36,19), com peso entre 98 a $266 \mathrm{~kg}$, IMC médio de 47,38 kg/m² (36 a 86). A Hipertensão era associada em 26,53\%, afecções ortopédicas $10,20 \%$ e diabetes $6,12 \%$. A técnica cirúrgica foi o by pass gástrico à Capella. Os pacientes foram acompanhados avaliando a perda de peso.

RESULTADOS: A operação produziu perda de peso significativa e durável, sendo em média 13,4 kg no $1^{\circ}$ mês, $25 \mathrm{~kg}$ no $3^{\circ}$ mês, $38,6 \mathrm{~kg}$ no $6^{\circ}$ mês, $46,6 \mathrm{~kg}$ em um ano e $51 \mathrm{~kg}$ em 2 anos. CONCLUSÃO: A obesidade é uma doença grave e cada vez mais comum, com a dieta raramente produzindo uma perda de peso mantida nesses pacientes, tornando a cirurgia o tratamento de escolha com bons resultados.

\section{PERFIL DAS VÍTIMAS FATAIS DE TRÂNSITO ATENDIDAS NO HPS JOÃO XXIII}

\section{Rodrigues Júnior, JB.; Roque, FS..; Drumond, DAF.; Bordoni, LS.; Oliveira, ACMB. Hospital João XXIII / Instituto Médico Legal, Belo Horizonte, Minas Gerais.}

A região metropolitana de Belo Horizonte possui apenas um Instituto Médico Legal. O hospital João XXIII é o centro de referência em trauma de Minas Gerais. Busca-se melhor compreensão dos casos de óbito relacionados a trânsito que foram atendidos no HPS João XXIII e, sobrevindo o óbito, necropsiados no IML-BH. Foram analisados 2271 laudos de necropsias realizadas no IML-BH no período de janeiro de 1997 a dezembro de 1998. Em 1292 casos havia evidência de atendimento médico, 43,96\% com referência ao HPS João XXIII. O grupo estudado então foi de 568 vítimas. A idade variou de 1 a 89 anos, com média de 37,3 anos. Os faiodermas representaram $54,4 \%$ dos casos estudados; e o sexo masculino $76,8 \%$. A média de altura foi 163,56 cm. O traumatismo crânio encefálico (TCE) esteve presente em 90,9\% dos casos, o traumatismo torácico em $83,4 \%$, o trauma abdominal em $70,7 \%$, as lesões de membros superiores em $69,9 \%$ e as de membros inferiores em 74,3\%. Os traumas pélvicos foram diagnosticados em $8,6 \%$ dos casos e os traumas de coluna em 4,6\%. Destes, $88,5 \%$ envolveram a coluna cervical, $7,7 \%$ a coluna torácica e 3,8\% a coluna lombar. O TCE foi considerado a causa de óbito em 40,4\% dos casos, o choque hipovolêmico em $20,8 \%$ e a sepse em 19,2\%. Portanto, segundo a amostra em estudo, o perfil da vítima fatal de acidente automobilístico que chegou a ser atendido no hospital João XXIII é adulto jovem, masculino, faioderma, politraumatizado, com alto índice de trauma craniano.

\section{VÍTIMAS FATAIS DE TRÂNSITO: ANÁLISE DA CAUSA MORTIS EM 2271 CASOS}

\section{Rodruges Júnior, JB.; Roque, FS.; Drumond, DAF.; Bordoni, LS.; Oliveira, ACMB. Hospital João XXIII / Instituto Médico Legal, Belo Horizonte, Minas Gerais, Brasil.}

Pretende-se com este estudo analisar o perfil das causas de óbito das vítimas de acidentes de trânsito de Belo Horizonte nos anos de 1997 e 1998. Foram recuperados 2271 laudos de necropsias desta natureza neste período, as causas dos óbitos catalogadas e analisadas no programa EpiInfo. 0 trauma crânio-encefálico (TCE) foi considerado causa do óbito em $42,9 \%$ dos casos, o choque hipovolêmico em $24 \%$, politraumatismos em $20,2 \%$, infecções em $10,4 \%$, traumas vertebrais em $1,2 \%$ e 1,0\% para outras causas. Foram diagnosticadas fraturas pélvicas à necropsia em 8,9\% dos casos e lesões de coluna vertebral em 5,6\%. Destas, 82\% acometeram a coluna cervical e $14,8 \%$ a coluna torácica. Nos pacientes onde a causa de morte foi politrauma e a pesquisa de teor alcoólico foi positiva, a média destes valores foi 12,3 dg/L. 0 TCE representa a principal causa de morte neste estudo nas vítimas de acidente de trânsito. Como a pesquisa radiológica disponível no Instituto é direcionada a procura de projéteis de arma de fogo, é razoável acreditar que os traumas ósseos em geral tenham sido subnotificados. 


\section{TRAUMA CRÂNIO-ENCEFÁLICO NA CRIANÇA}

Rodrigues Júnior, JB.; Roque, FS.; Bordoni, LS.; Oliveira, ACMB.; Guerra, SD. Hospital João XXIII / Instituto Médico Legal, Belo Horizonte, Minas Gerais, Brasil.

Na criança até 2 anos o diâmetro cefálico é proporcionalmente maior que em outras faixas etárias e o crânio não é uma estrutura de proteção rígida. O trauma crânio-encefálico (TCE) neste grupo, consequientemente, possui maior gravidade proporcional em relação a idades. Com o propósito de conhecer mais acerca do TCE nestes pacientes, busca-se analisar necropsias de vítimas de trânsito com idade abaixo de 2 anos realizadas no IML de Belo Horizonte onde houve algum acometimento cefálico. Foram analisados 16 laudos de necropsias de acidentes de trânsito nos anos de 1997 e 1998 em indivíduos abaixo de 2 anos. Destes, houve algum acometimento cefálico em 15 casos $(93,7 \%)$, constituindo o grupo de estudo. O sexo feminino perfez 9 casos $(56,3 \%)$. A média de altura foi de 70,6 cm. Houve fraturas de crânio em 9 casos $(56,3 \%)$, sendo que destas, 2 foram em osso isolado e $7 \mathrm{em}$ mais de um osso craniano. As fraturas de abóbada foram observadas em 7 casos $(43,8 \%)$ e as de base em 5 (31,3\%), sendo que em 4 casos houve combinação destas. A hemorragia intracraniana esteve presente em 12 casos (75\%) e as lesões de face em 2 casos. A causa da morte foi TCE em 7 casos $(43,8 \%)$ e politraumatismo em 3 casos. Este estudo confirma a literatura específica no que se refere à presença de lesões cranianas múltiplas em crianças e à ausência de fraturas em grande parte delas. Entretanto, apresenta percentual relativamente baixo no que se refere a TCE como causa do óbito.

\section{TRAUMA NO IDOSO EM ACIDENTES DE TRÂNSITO: ANÁLISE DE 217 CASOS}

Rodrigues Júnior, JB.; Roque, FS.; Drumond, DAF.; Bordoni, LS.; Oliveira, ACMB.

\section{Hospital João XXIII / Instituto Médico Legal, Belo Horizonte, Minas Gerais.}

O indivíduo traumatizado com idade acima de 65 anos representa um grupo especial com relação a suas reservas fisiológicas e resposta endócrino-metabólica à agressão. Os acidentes automobilísticos constituem uma importante causa de morbidade e mortalidade neste grupo etário. Com o propósito de conhecer mais acerca das lesões sofridas por idosos, vítimas fatais de acidentes de trânsito, busca-se analisar necropsias desta natureza realizadas no Instituto Médico Legal de Belo Horizonte. Foram recuperados 217 laudos deste tipo nos anos de 1997 e 1998. As idades variaram de 65 a 89 anos, com média de 73,4 anos. O sexo masculino perfez $65,9 \%$. A média de altura foi de $163,2 \mathrm{~cm}$ e $59,4 \%$ eram leucodermas. Havia sinais de atendimento médico em $68,6 \%$ dos casos. O trauma crânio-encefálico (TCE) esteve presente em $84 \%$ dos casos, o torácico em $84 \%$, o abdominal em $65 \%$, o de membros inferiores em $80 \%$ e o de membros superiores em 73\%. Em 12\% dos casos houve diagnóstico de trauma pélvico e em 4,6\% de lesão de coluna vertebral, sendo que 50\% destas acometeram o segmento cervical. A causa do óbito foi choque hipovolêmico em $33,2 \%$, TCE em $30 \%$, politraumatismo em $21,2 \%$ e infecções em $13,4 \%$. Nos laudos onde a causa do acidente foi recuperada, $85,9 \%$ foi devido a atropelamento. Este trabalho reforça o conceito de que o trauma devido a acidentes de trânsito no idoso possui tendência a acometimento global e destaca a importância da perda volêmica como causa de óbito nesta faixa etária.

\section{VÍTIMAS FATAIS DE ACIDENTES DE TRÂNSITO ENTRE 0 E 18 ANOS: ANÁLISE DE 340 CASOS.}

Rodrigues Júnior, JB.; Eoque, FS.; Bordoni, LS.; Oliveira, ACMB.; Guerra, SD. Hospital João XXIII / Instituto Médico Legal, Belo Horizonte, Minas Gerais

A criança e o adolescente representam grupos especiais entre os pacientes vítimas de acidentes de trânsito, pois de acordo com certas faixas etárias variam o tipo mais comum de lesão bem como a resposta fisiológica à agressão. Com o objetivo de melhor conhecer este grupo de pacientes, foram analisados 2271 laudos de necropsias de trânsito realizadas no Instituto Médico Legal de Belo Horizonte no período de janeiro 
de 1997 a dezembro de 1998. Destes, 340 (14,9\%) eram vítimas com idade variando de 0 a 18 anos. Estes 340 casos constituíram o objeto do estudo. A média de idade foi de 11,7 anos, sendo que a faixa etária com maior número de casos foi a de 12 a 18 anos, com 203 vítimas (59,7\%). Pertenciam ao sexo masculino 66,5\% do total, mas na faixa abaixo de 7 anos as mulheres constituíram o maior grupo. A média de altura foi de $143 \mathrm{~cm}$ e 58,5\% eram faiodermas. Houve menção a algum tipo de atendimento médico (hospital ou unidades de pronto atendimento) em 59,5\% dos pacientes e 40,5\% faleceram no local. A causa da morte foi atribuída a trauma crânio-encefálico (TCE) em 54,4\% dos casos, a politraumatismo em 16,5\%, a choque hipovolêmico também em $16,5 \%$, a sepse em $10,1 \%$ e outras causas em $2,5 \%$. Com base nos resultados deste estudo o perfil da vítima de acidente de trânsito na faixa etária de 0 a 18 anos é masculino, faioderma, média etária de 11,7 anos e com alta incidência de TCE.

\section{TEMA LIVRE MONOGRAFIA}

\section{ANTIINFLAMATÓRIOS NÃO ESTERÓIDES E OPIÓIDES}

Carneiro, BGMC.

\section{Faculdade de Medicina da UFMG}

As drogas antiinflarriatórias não esteróides (AINES) compreendem um grupo heterogêneo de compostos que compartilham efeitos terapêuticos e colaterais. 0 ácido acetilsalicílico, protótipo deste grupo de drogas, foi inicialmente sintetizado na Alemanha em 1899 e com o tempo várias drogas com ação semelhante foram sendo produzidas. A ação antiinflamatória dos AINES decorre da inibição da produção das prostaglandinas, pela inibição da enzirria cicloxigenase (COX) 1 e 2.0 surgimento de novos AINES, inibidores seletivos da COX-2, agem preferencialmente no processo inflamatório, evitando muitos efeitos colaterais. Os AINES são eficazes em dores de baixa a média intensidade, podendo ser usados no pós-operatório de algumas cirurgias. Além disso, atuam no hipotálamo reduzindo a temperatura em processos febris e na inflamação, sendo muito importantes no tratamento de distúrbios musculoesqueléticos. 0 efeito colateral mais comum é a propensão a induzir ulceração gástrica.

Os opióides são um grupo de drogas relacionadas ao ópio ou à morfina. A morfina foi isolada do ópio pela primeira vez em 1806 e recebeu este nome em homenagem a Morfeu, deus grego dos sonhos. A ação dos opióides se dá através da ocupação dos receptores opióides do organismo, mimetizando a ação dos peptídeos opióides endógenos. Eles são usados principalmente como analgésicos, aliviando o sofrimento através da alteração do componente emocional da experiência dolorosa, sendo muito úteis na dor da doença terminal e do câncer. Devido às alterações causadas pelo trauma cirúrgico, pode ser feita a analgesia pré, per ou pós-operatória com estas drogas, de acordo com o tipo de cirurgia. Outra importante função dos opióides é o seu uso como anestésico. Os efeitos colaterais mais temidos, relacionados à dose empregada e ao tempo de uso são, a curto prazo, depressão respiratória e a longo prazo, dependência.

\section{FÍSTULAS ENTÉRICAS PóS-OPERATÓRIAS: QUANDO REOPERAR?}

Costa, MBS.

\section{Instituição: Faculdade de Medicina da UFMG}

As fístulas digestivas estão entre as mais temíveis complicações pós-operatórias. A mortalidade para a maioria dos procedimentos eletivos é atualmente inferior a $5 \%$, variando de 6,45 a $48 \%$ na maioria das séries publicadas sobre fistulas digestivas.

Diversos fatores podem predispor o aparecimento de fístulas entéricas pósoperatórias: fatores gerais $\longrightarrow$ idade avançada, sepse e desnutrição; e fatores locais $\longrightarrow$ infecção local, material de sutura, telas e próteses. As causas mais freqüentes de aparecimento de fístulas pós-operatórias são: deiscência de anastomose; ação traumática de drenos e tubos; e lesões traumáticas acidentais não percebidas na cirurgia. 